\title{
Simulation as a Support for Ultrasonic Testing
}

\author{
Pavel Mares \\ Structural and System Diagnostics, Research Centre Rez Ltd., Husinec-Rez, Czech Republic \\ Email: Pavel.Mares@cvrez.cz
}

Received 6 May 2014; revised 2 June 2014; accepted 27 June 2014

Copyright @ 2014 by author and Scientific Research Publishing Inc. This work is licensed under the Creative Commons Attribution International License (CC BY). http://creativecommons.org/licenses/by/4.0/

c) (i) Open Access

\begin{abstract}
Ultrasonic testing is a very important non-destructive method for testing components for safety of nuclear power plants and other security and delicate parts in other industries. Nowadays, thanks to the development of computer technology, it is possible to simulate processes which occur during ultrasonic testing. That is why numerical simulations are becoming an integral part of non-destructive testing. Simulations are used to determine parameters of ultrasonic examination, especially parameters of probes and scan plan and also in the analysis of results. They are used in such cases, when it is necessary to verify applicability of probes and methods. This verification could be provided on the weld and test block which are not manufactured. It could be also provided on defects, which are not manufactured in test block, but their presence is possible in given weld joint. Simulations are very useful for verifying the propagation of ultrasonic signal in given area (e.g. weld area). If movement of probe is limited, possibility of whole volume scan should be verified.
\end{abstract}

\section{Keywords}

Non-Destructive Testing, Ultrasonic, Simulation, Phased Array

\section{Introduction}

Modeling and simulation of ultrasonic non-destructive testing is utilized in ever-increasing number of industrial NDT including nuclear power plants. The application is beneficial in various fields, such as evaluation and analysis of recorded data, modeling of ultrasonic inspection process, proposals of geometry of probes, proposals of inspection procedures and more [1].

Goal of this paper is to describe main advantages of ultrasonic simulation software and its usage in the field of ultrasonic examination. We find that combination of three tools (raypath, ultrasonic field computation, computa- 
tion of response from defects) is very useful and in some cases it is necessary. Simulation of NDT is an essential part of qualification and inspection procedures in Czech Republic. In chapter 3, these three tools are described with some examples made by the author of this article.

\section{Techniques of Ultrasonic Testing}

The ultrasonic principle is based on the fact that solid materials are good conductors of sound waves. Whereby, the waves are not only reflected at the interfaces but also by internal flaws (material separations, inclusions etc.). The interaction effect of sound waves with the material is stronger the smaller the wave length, this means the higher the frequency of the wave.

$$
\lambda=\frac{c}{f}
$$

This means that ultrasonic waves must be used in a frequency range between about $0.5 \mathrm{MHz}$ and $25 \mathrm{MHz}$ and that the resulting wave length is in $\mathrm{mm}$. With lower frequencies, the interaction effect of the waves with internal flaws would be so small that detection becomes questionable cases where the highest safety requirements are demanded (e.g. nuclear power plants, aerospace industry) [2].

Ultrasonic Testing uses high frequency sound energy to conduct examinations and make measurements. Ultrasonic inspection can be used for flaw detection/evaluation, dimensional measurements, material characterization, and more. A typical UT inspection system consists of several functional units, such as the pulser/receiver, transducer, and display devices. A pulser/receiver is an electronic device that can produce high voltage electrical pulses. Driven by the pulser, the transducer generates high frequency ultrasonic energy. The sound energy is introduced and propagates through the materials in the form of waves. When there is a discontinuity (such as a crack) in the wave path, part of the energy will be reflected back from the flaw surface. The reflected wave signal is transformed into an electrical signal by the transducer and is displayed on a screen [3].

\subsection{Pulse Echo Technique}

Pulse-echo ultrasonic measurements can determine the location of a discontinuity in a part or structure by accurately measuring the time required for a short ultrasonic pulse generated by a transducer to travel through a thickness of material, reflect from the back or the surface of a discontinuity, and be returned to the transducer.

\subsection{Phased Array Technique}

Phased array technique is currently the most advanced technique for ultrasonic testing. This technique is only an extension of pulse echo technique. The biggest difference compared to the pulse echo technique is in design of transducer. Phased array probe consists of a series of individual transducer elements placed in one house. Excitation of elements is controlled electronically and it is possible to change parameters of transducer and ultrasonic beam, e.g. dimension of transducer, angle and focal point of ultrasonic beam, etc.

With phased array probe it is possible to use several types of scanning, e.g. electronic scanning, sectorial scanning, etc.

\subsection{Time of Flight Diffraction Technique}

Time-of-flight diffraction (TOFD) method of ultrasonic testing is a sensitive and accurate method for the non-destructive testing of welds.

Measuring the amplitude of reflected signal is a relatively unreliable method of sizing defects because the amplitude strongly depends on the orientation of the crack. Instead of amplitude, TOFD uses the time of flight of an ultrasonic pulse to determine the position of a reflector. This technique consists of two transducers (emitter and receiver oriented in opposite directions) and is used to detect and size planar flaw by observing their top or/and bottom edges of diffraction echoes.

\section{Simulation of Non-Destructive Testing}

It is possible to use simulations for interpretation of results obtained by examination. For imaging of results all basic types of US images and their transformations can be used, which can serve e.g. for imaging of results in 
3D model. On the basis of comparison of obtained US signal images it is possible to identify echoes which are obtained from defects with the help of simulation software, e.g. verifying of diffraction echo existence, separation of geometric echo from echo from defect, etc. Three main tools for simulations of ultrasonic testing are described in next chapters.

\subsection{Raypath}

Function of this tool is generating an image by tracing the path of ultrasonic waves in the test environment. Displayed lines represent the axis of the probe ultrasound beam with application of idealized reflection and transformation properties of the ultrasound signal. Signal amplitude is not considered in this tool. This tool could take into account different types of waves and these waves could be color coded. This tool may also take into account conversion of waves during reflection. Figure 1 shows propagation of ultrasonic beam by angel probe. This beam is reflected on defect and on inner surface. Transformation from longitudinal to shear waves is also possible to see. Green color is for longitudinal waves and red for shear waves. This example is from our project on NDT qualification of nozzle to main circulation pipeline weld joint. This weld joint is located on nuclear power plant of VVER 440 type.

\subsection{Ultrasonic Field Computation}

Ultrasonic field computation is used to display propagation area of ultrasonic beams. On the market, there are some software that deal with the calculation of ultrasonic field. This tool could be used for:

\section{- Design of the phased array probe}

Simulation of ultrasonic field is very important for the design of ultrasonic probes, especially in the case of phased array probes. It is very important to design correct aperture and number of elements to avoid unwanted grating lobes. Figure 2 shows correct design of a phased array probe with 32 elements. There is possible to see clear ultrasonic beam in refraction angle $40^{\circ}$ in steel material. Figure 3 shows undesirable design of phased array probe with the same aperture like previous probe, but only with 8 elements. It is possible to see strong grating lobe a weak ultrasonic beam for refraction angle $40^{\circ}$ [4].

- Coverage of inspected volume by acoustic pressure

Another use of ultrasonic field simulation is when sectorial scanning is used and it is necessary to find out coverage of inspected volume by ultrasonic beam. Figure 4 is an example of inspection volume coverage by phased array probe and sectorial scanning. Range of refraction angles are between $45^{\circ}$ to $70^{\circ}$. This example is from our project on NDT qualification of steam generator collector weld, which is located on Nuclear power plant Temelin in Czech Republic.

\subsection{Computation of Response from Defects}

Simulations are conducted to determine the optimum measurement parameters. Such parameters should be set

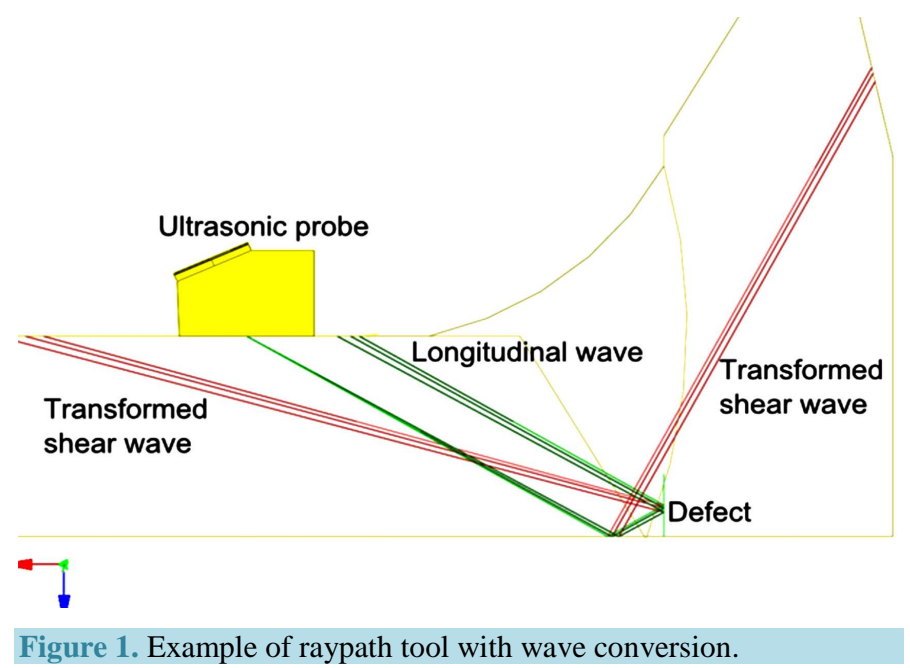




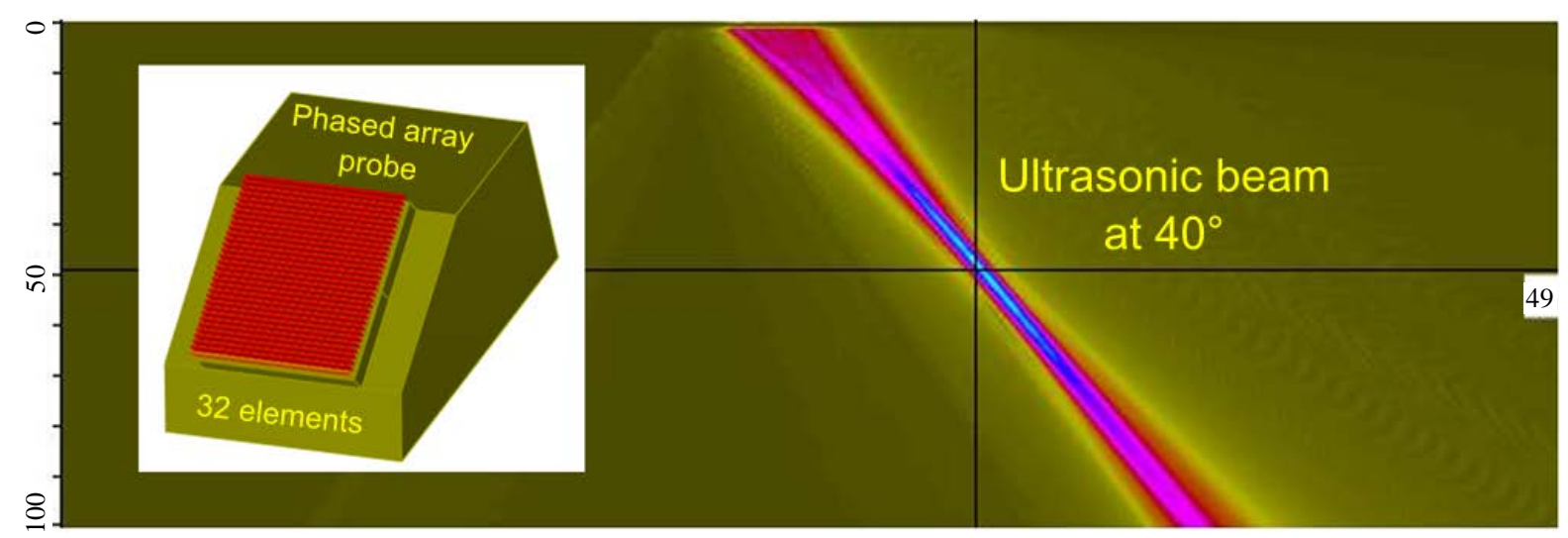

Figure 2. Phased array probe with 32 elements.

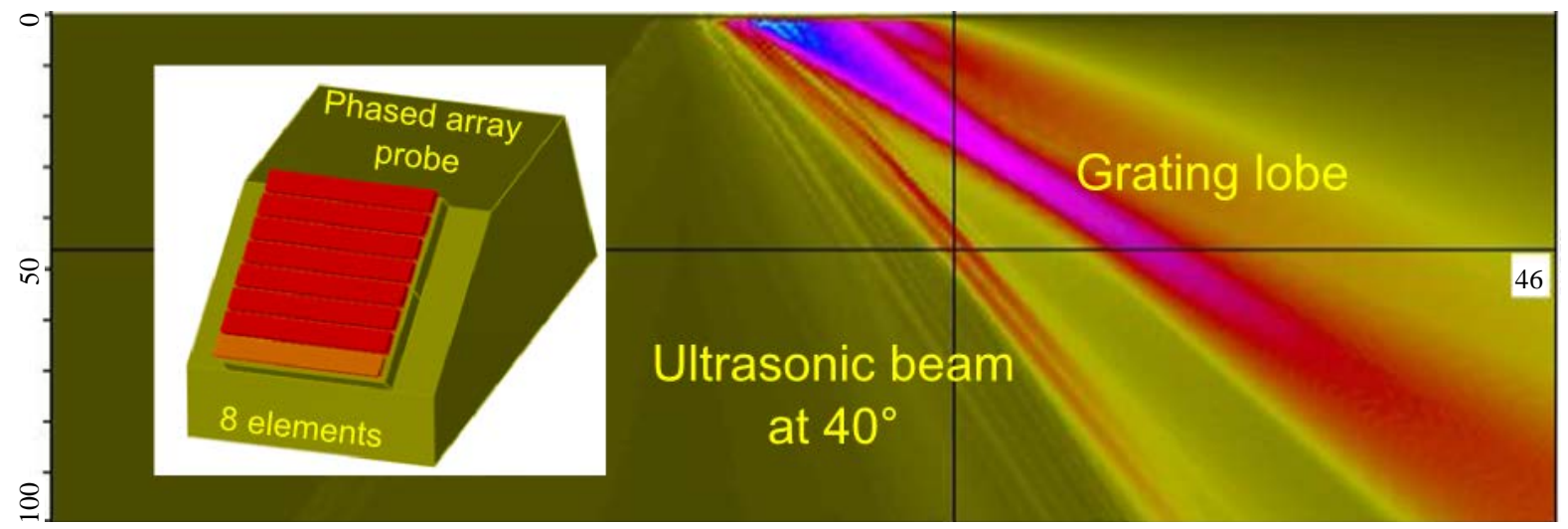

Figure 3. Phased array probe with 8 elements and unwanted grating lobe.

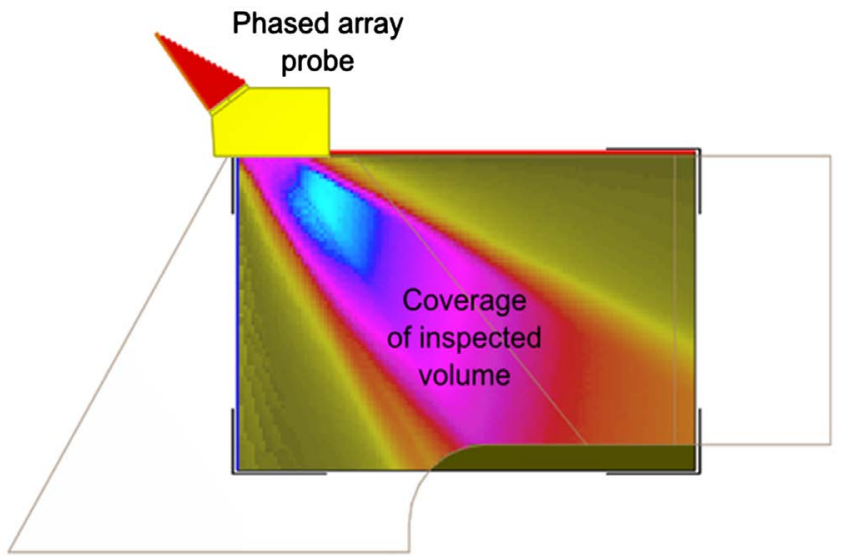

Figure 4. Coverage of inspected volume by sectorial scanning and phased array probe.

exact to detect defects during examination and meet with the criteria imposed for the current trial. Another application of simulation is in the process of evaluating the results of the examination. It means helping with identification of obtained echo-signals, design of calibration or test block, verifying of test equipment parameters, etc. In Figure 5, it is possible to see result from real examination compared to the results from simulation. This response is from real lack of fusion in the weld root. We found this lack of fusion in test block, which was used for qualification welders. This qualification was made for preparation of weld joint in steam generator collector repairs on nuclear power Dukovany in Czech Republic. 

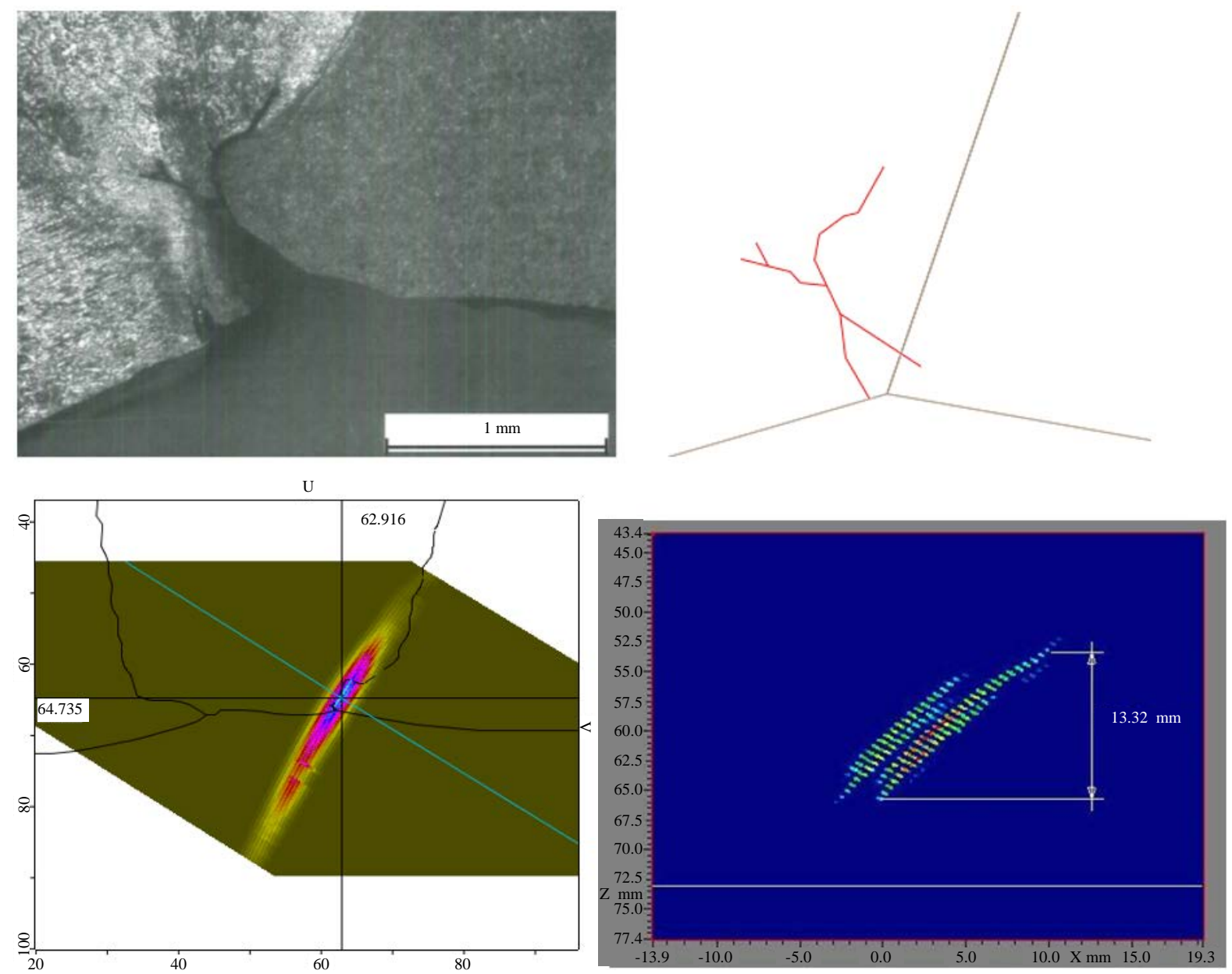

Figure 5. Real lack of fusion defect (left top), lack of fusion in simulation (right top), response from defect in simulation (left bottom), response from defect in real examination (right bottom).

\section{Conclusion}

Suitable assessments of inspected areas are necessary conditions for covering of safety service of important components in industry, especially at nuclear power plants. Implementing the new non-destructive methods and other supporting activities like computer modeling ensures increasing of examination quality of selected areas. That is why computer modeling is becoming an integral part of non-destructive testing. Examinations are extended by other additional information with the help of computer modeling. Other benefits are the possibilities to predict responses from defects, which are not manufactured in test block or even a simulation of a whole test block, which is not manufactured; or verification of usage of certain probe or method which belongs to possibilities of utilization of simulations.

\section{Acknowledgements}

The author would hereby express his greatest thanks to the SUSEN Project (CZ.1.05/2.1.00/03.0108), realized in the framework of the Operational Programme Research and Development for Innovations of the European Regional Development Fund (ERDF), for the financial support of the research.

\section{References}

[1] Mares, P., Horacek, L. and Vlcek, P. (2010) Recent Computer Activities and Achievements for UT Qualification of WWER Type NPPs Inspection Areas. Proceedings of the 8th International Conference on NDE in Relation to Structural Integrity for Nuclear and Pressurised Components, Berlin, 29 September-1 October 2010, 127-133. 
[2] Kratkrämer, J. (1990) Ultrasonic Testing of Materials. 4th Edition, Springer-Verlag, Berlin.

[3] NDT Education Resource Center. http://www.ndt-ed.org/

[4] Neupauer, J. (2013) Praktickévyužitiemodelovaniaprinávrhu a výberesondy Phased Array. Presentation on Sympózium Slovcert, Senec, 16-17 October 2013. 
Scientific Research Publishing (SCIRP) is one of the largest Open Access journal publishers. It is currently publishing more than 200 open access, online, peer-reviewed journals covering a wide range of academic disciplines. SCIRP serves the worldwide academic communities and contributes to the progress and application of science with its publication.

Other selected journals from SCIRP are listed as below. Submit your manuscript to us via either submit@scirp.org or Online Submission Portal.
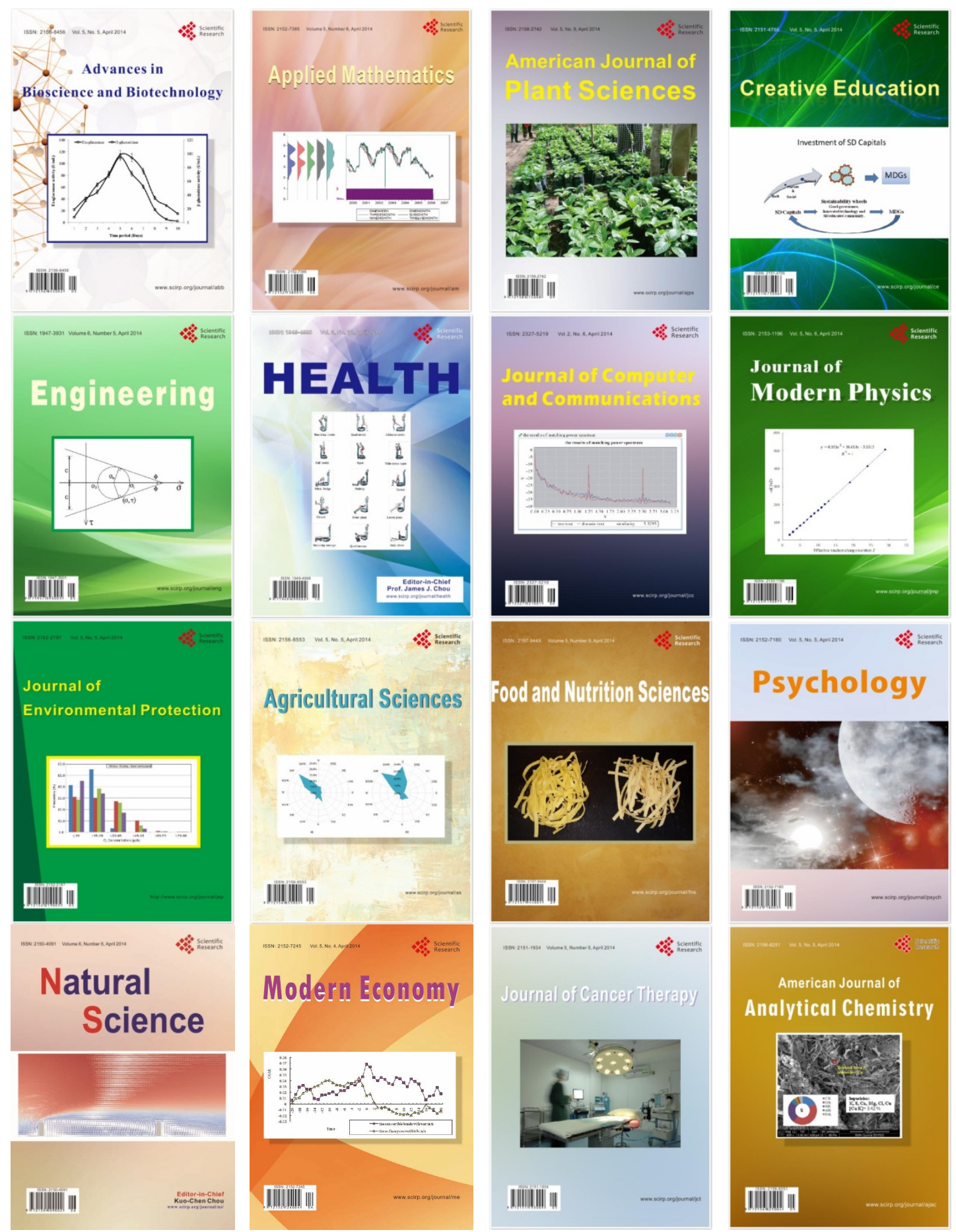